\title{
Powerful knowledge? A multidimensional ethical competence through a multitude of narratives
}

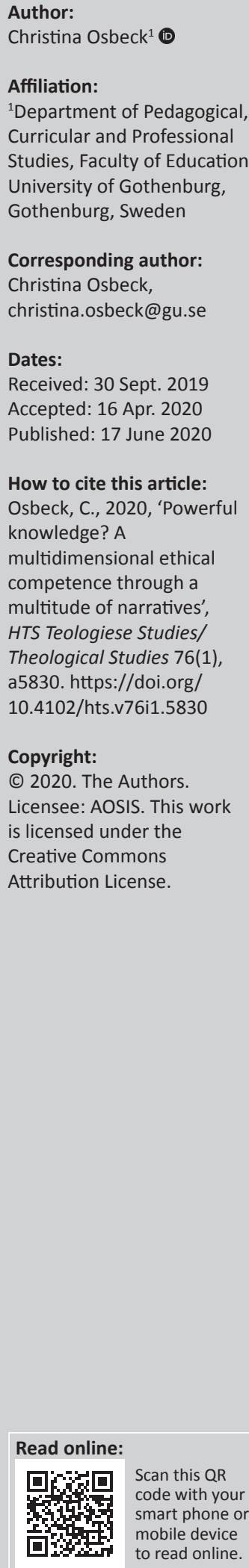

High-quality education has been considered important for social justice, although what good education means is contested. A project aimed at identifying varieties of conceptions of ethical competence (EthiCo) was presented as well as another that focused on a fictionbased approach to ethics education (EE). A multidimensional ethical competence mediated through a multitude of narratives was shown as a strong contribution to EE. The aim was to discuss as to what extent such a multidimensional ethical competence mediated through a multitude of narratives could be understood as powerful knowledge. Sweden, where national tests lately have been understood as a tool to increase achievements, but where an unclear understanding of desired knowledge in EE exists, was the setting. Methodologically, the article drew on Michael Young's definition of powerful knowledge, a hermeneutic meta-study on the findings of EthiCo concerning conceptions of ethical competence, as well as Mark Tappan's sociocultural perspective on moral development. These perspectives were brought together to discuss powerful knowledge in EE as a contribution to education for social justice. Whether a multidimensional ethical competence mediated through a multitude of narratives could be understood as powerful knowledge was shown to be dependent on the definition. Whilst Young's powerful knowledge is restricted to an academic language, Tappan stresses vernacular language as characteristic for a functional moral discourse. One conclusion was the centrality of fiction in EE for the development of moral discourses that transcend reality and shape 'knowledge of possibilities' - powerful in the shaping of societal justice.

Keywords: Ethics; Moral; Competence; Powerful knowledge; Fictions.

\section{Introduction}

A high-quality education for all children can be understood as an important factor for developing social mobility and social justice in society. However, what is considered good education is a contested issue, related to different theoretical perspectives on learning and teaching. In Sweden, compulsory school and its curriculum have for decades been strongly influenced by a progressive pedagogy, whereby the activity of the knowledge-searching pupil and their own experiences have been central (Samuelsson 2014). In recent years, however, this pedagogic paradigm has been challenged from different perspectives (Osbeck \& Skeie 2014).

\section{Powerful knowledge}

One strand in the challenges of a progressive pedagogy that has drawn a great deal of attention in Swedish subject-matter education research lately is the perspective on 'powerful knowledge', launched by the British educational researcher Michael Young (2013a, 2013b). This challenge involves the doubt concerning the potential of such a pedagogy to develop powerful knowledge for all children. Powerful knowledge is seen as existing in a dyadic relationship with 'knowledge of the powerful', whereby it is impossible to reduce either of them to the other (Young 2013b). In society, there are real social hierarchies through which knowledge of the powerful also becomes powerful knowledge; however, this does not mean that powerful knowledge can be any kind of knowledge. Powerful knowledge helps us understand and explain the world in better ways (Young 2013b). There is a belief in '...better knowledge, more reliable knowledge, knowledge nearer to truth about the world we live in and to what it is to be human' (Young 2013a:107). In a critique of progressive tradition, Young (2013a) states the following:

It follows from this view that the question that teachers are faced with becomes limited to 'is this curriculum meaningful to my students?' rather than 'what are the meanings that this curriculum gives my

Note: Special collection entitled Ethics, education and social justice, sub-edited by John Klaasen (UWC). 
students access to?' or 'does this curriculum take my students beyond their experience and enable to envisage alternatives that have some basis in the real world?' (p. 106)

All schoolchildren have the right to be offered powerful knowledge, for which disciplinary and specific language is regarded as central because it offers the possibility to transgress the limitations of everyday life practices and contextual knowledge. The differentiated and specialised knowledge is regarded as superior to the contextually bound everyday life language. Abstract knowledge has a wider scope and could be applied to different kinds of practices whereas everyday life discourse is more contextually bound.

\section{Aim}

Ethics education (EE) is a school subject like any other subject, and consequently, following Young, should contribute to developing pupils' powerful knowledge, to high-quality education and to social justice. This article presents conditions for EE in Sweden, together with an overview of findings within the EthiCo research project, that is, 'What may be learnt in ethics? Varieties of conceptions of ethical competence to be taught in compulsory school', 2014-2018, funded by the National Research Council and conducted by Olof Franck, Johan Tykesson, Annika Lilja, Karin Sporre and the present author. The project has largely focused on the didactical 'what' question concerning conceptions of ethical competence. This article also sketches out the foundation of a newly founded follow-up research project with interest in the didactical 'how' question concerning how an ethical competence could be understood to develop. In this way, the structure of the article - that is its different sections - enables the discussion of powerful knowledge in ethics, what this can mean, and more precisely enables a discussion of the following main question of this article: To what extent could what we maintain in our research as the importance of a multidimensional ethical competence mediated through a multitude of narratives be understood as powerful knowledge?

\section{National tests and a need for a broader conception of ethical competence}

Whether or not related to strong support for a progressive pedagogy, Swedish schools have struggled with decreased achievement and increased differences between pupils (Yang Hansen \& Gustafsson 2016). Here also, perspectives similar to Young's 'powerful-knowledge perspective' have been heard in the debate. For instance, it has been stressed that pupils who primarily have access to basic knowledge through school are the biggest losers when the school prioritises know-how-to-get information over basic knowledge. Such a development could be understood as resulting in decreased possibilities for the school to be an instrument of social mobility (e.g. Frykman 1998). Simultaneously, one should be aware that the decreased achievements of Swedish schools have correlated with large system changes in education. Amongst the most important of these changes are the decentralisation of educational authority and the development of independent schools (e.g. Claesson \& Strandler 2016).

One strategy used by the government in an attempt to regain control in the decentralised educational system and try to improve poor achievement, documented, for instance, by international testing, has been to launch more national testing. Such a strategy is of course ambiguous because of, amongst other things, the fact that even if achievement levels improve, this does not necessarily mean more meaningful and relevant teaching and learning (cf. Conroy, Lundie \& Baumfield 2012). One of the new subjects in which testing was introduced in 2013 was religious education (RE), in which ethics is one knowledge area. The commission to conduct tests was given by the Swedish National Agency for Education (Skolverket 2011) to the Department of Pedagogical, Curricular and Professional Studies, University of Gothenburg. One note that was made by test constructors at an early stage was that ethics seemed to be a rather marginalised knowledge area in relation to the dominant 'world religions', a pattern that also mirrors the name of the subject (Lindskog 2014; Mårdstedt \& Wåke 2014).

As ordinary schoolteachers (according to the Swedish test system) are those performing the assessment of pupils' responses based on assessment instructions, and Ethics seemed to be a marginalised knowledge area, a study focussing on the teachers' assessment seemed motivated. A think-aloud study was conducted (Osbeck et al. 2015) with the aim to identify and discuss challenges in assessing pupils' knowledge in ethics. Three groups of challenges related to the assessment processes were identified: the first pertained to interpretations of assessment instructions; the second regarded competing ideas about what students should be given credit for during assessment in ethics; and the third involved being positioned between the pupil's need for good grades and the task of differentiating between students. Whilst the first and third groups of challenges could be understood as general challenges in assessment, the second was specifically related to ethics. In the discussion of these findings, the vagueness of ethics in the Swedish curriculum was stressed upon, for instance, duality in the aims of curriculum. It was concluded that if a knowledge field is vague, then the influence of national tests is assumed to be significant, and there is an urgent need for research regarding different conceptions of ethical competence to broaden policy and teaching.

\section{Research, material and methods}

From the perspective of a necessary broadening of understanding of ethical competence, the EthiCo project, or more precisely - 'What may be learnt in ethics? Varieties of conceptions of ethical competence to be taught in compulsory school' - was developed by Olof Franck, Annika Lilja, Karin Sporre, Johan Tykesson and the present author. The project's empirical starting point was material from the first test round of 
national assessment of ethics within RE. The project critically examined how ethical competence was operationalised therein. The character of the ethical competence of the test was then compared in relation to other ethical competences related to different curriculum levels, such as institutional, instructional and experiential (e.g. Bråten 2009; Goodlad \& Su 1992).

Although ethics as a knowledge field in Sweden is placed in 'Religious Education', it is highlighted in general parts of curriculum. In these parts, ethical competence could be interpreted as mainly showing certain fundamental values, whilst the knowledge requirements for the subject of RE rather stress upon analytical and argumentative skills. The introduction of national tests in RE (and ethics) exposed this contradiction. The fact that every fourth child in grades 6 and 9 will be evaluated every year as having or not having approved knowledge in ethics stresses the question as to what constitutes relevant knowledge in ethics. Also, the general question as to the meaning of a compulsory school teaching of ethics could be understood as thereby emphasised.

Against this background, the purpose of the EthiCo project was formulated: to identify and elucidate varieties of conceptions of ethical competence, and critically analyse and discuss them in relation to each other, as well as to ethical theory, as a potential educational content in compulsory school. Besides theoretical perspectives - represented by Benhabib (1992, 2006), Løgstrup (1997), Nussbaum (1990, 2008, 2011) and Singer (2011) - the varieties of ethical competence were studied from policy perspective and from the perspective of teachers and pupils. The project was ethically vetted and approved (Dnr 060-15) by the regional ethical review committee for research.

In this article, an overview of findings within the EthiCo research project, based on different types of empirical studies, is presented. By bringing these findings together, not only the results of separate studies are shown but also depicted an overarching result pattern of the research project. In this way, the article is a meta-study, drawing on separate studies and bringing them together.

This article expands the empirical studies of the EthiCo project and the didactical 'what' question concerning conceptions of ethical competence. Besides, the article sketches out a newly founded follow-up research project with interest in the didactical 'how' question, that is, how ethical competence could be understood to develop, and also highlights the sociocultural foundation of the project. ${ }^{1}$ Together, these two research projects emphasise ethical competence as a multidimensional ethical competence mediated through a multitude of narratives. Given this foundation and a hermeneutical approach, it is possible to discuss the specific research question of this article, that is, to what extent could this multidimensional ethical competence referred to with the Dnr 588-17. mediated through a multitude of narratives be understood as powerful knowledge?

\section{EthiCo: Researching conceptions of ethical competence}

The EthiCo project was developed from the starting point that there are reasons to believe that the knowledge requirements and national tests limit central knowledge in ethics, that is, there may be broader conceptions of ethical competence than the stated analytical and argumentative competences. Analyses of national tests and their constructions have shown that not least the knowledge requirements of the syllabus of RE direct the test's focus such that primarily reasoning in ethics, an argumentative and conceptual competence, is tested; this, in turn, also means that EE is voided of crucial content (Sporre 2019).

Furthermore, comparisons with international curricula, such as other Nordic curricula, show, for instance, an absence of action competence (Lilja et al. 2018). Policy analyses from Namibia, South Africa, California and the Province of Québec also have pointed to the importance of formulating ethical competence in dialogue with contemporary social challenges and not shying away from morally complex issues such as class, gender and race. From a comparative perspective, absence of issues related to race and racism in the Swedish curriculum was especially striking (Sporre in press).

Not only the policy studies but also the analyses of teacher perspectives on central ethical competences for their pupils to develop widen the perspectives in relation to the analytical and argumentative perspectives of Swedish curriculum (Lilja \& Osbeck 2019). In the interviews, teachers stress the importance of ethical competences to understand, act, verbalise and persevere, which furthermore differ in what they are directed towards and work in defence of, for example, oneself, others or the broader social context. These competences have also been understood in relation to interpretations of the ethicists Benhabib (1992, 2006), Nussbaum (1990, 2008, 2011), Løgstrup (1997) and Singer (2011), represented as the voice of rights, of responsiveness due to interdependence, of virtue and of reasoning for maximal utility. Through discussion of empirical and theoretical perspectives in relation to each other, teachers' nuanced understanding of their practice is shown, in line with previous research (e.g. Afdal 2005; Anker \& Afdal 2018), as is the importance of empirical abductive research.

In the EthiCo project, pupil perspectives on ethical competences were shown through analyses of several types of material. Based on the grades given to pupils in 2013 tests, quantitative analyses showed that these grades are generally lower for the subarea of ethics than for the subareas related to religions. This could be interpreted as not only that the ethics part of the subject is generally more difficult, but also that the format of these tasks, frequently involving open writing, are more complicated. Moreover, it is clear that girls generally perform better than boys on the RE national test and that 
native Swedish-speaking pupils perform better than nonnative Swedish-speaking pupils. Differential item functioning analyses were also conducted to identify test tasks that seem to favour one group of pupils over another, for instance, girls over boys, but no such task was identified for the area of ethics knowledge (Tykesson 2017).

Qualitative reanalyses of pupils' responses on national tests reveal that the conceptions of identified ethical competences vary in relation to the questions the pupils are asked (specific test tasks). Because the tests are designed in relation to the knowledge requirements of RE syllabus, meaning that they are constructed to identify a competence to analyse and argue, such competences are also, not surprisingly, present in responses. Despite this test construction, reanalyses of pupils' writings also show wider ethical competences. In particular, a competence to weigh values in relation to each other and argue for collective and societal values, in line with the introductory fundamental values of Swedish curriculum, is shown - although this does not receive credit in the test (e.g. Osbeck 2017).

In the interviews with pupils, ethical competence was shown as a rather contextual, holistic, procedural and everyday-liferelated competence, which also clearly includes the weighing of values in relation to each other. The needs expressed by pupils regarding ethical competence were related to certain situations, some of which were mentioned more frequently than others, such as peer relations, choices concerning one's education and the future, refugee situations, and begging. Mentioned situations, expressed values and the need for ethical competences were shown in the interviews to be intertwined. Examples of necessary ethical competence that were given included not only an identifying competence, an examining and weighing competence and a carrying out competence but also a reconsidering competence that is taking responsibility for one's previous decisions. In the emphasis on an examining and weighing competence, the pupils also stressed upon the importance of being aware of different options and in this sense being knowledgeable and well-informed (Osbeck 2018).

In summary, one may say that the EthiCo project, through the analyses of various empirical materials, shows varieties of conceptions of ethical competences beyond the analytical and argumentative ethical competences of Swedish RE syllabus and national tests. Ethical competences that could have been stressed upon in the Swedish RE syllabus include an identifying competence, concerning ethical dilemmas in everyday life; a weighing competence, in relation to collective and societal values; a competence of being wellinformed about the issues at stake (the phenomena that a current dilemma involves); an action competence; a perseverance competence; and a reconsidering competence, but also the competence to contextualise ethical issues in today's multicultural global society.

This summary of the empirical part of EthiCo project is in line with the findings from the systematic review of previous studies in ethics and moral education conducted within the project (Osbeck et al. 2018). The study focused on varieties of ethical competences, and showed similarities between the study's tentative formulation of identified ethical competences in four categories and Rest's (1986) understanding of acting morally, captured in the four components of sensitivity, judgement, motivation and implementation. The study showed the centrality of the components' moral sensitivity and moral implementation - and their relative absence in the Swedish curriculum - but also how moral judgement must include the competence to evaluate moral motivations, in which empirically testable reasons are central. In addition, the study highlighted the risk of neglecting contextual, situational and knowledge-related aspects of ethical competence - perspectives not highly visible in Rest's (1986) conceptualisation. Altogether, the EthiCo project - largely an educational 'what' project - showed ethical competence as a multidimensional competence, in contrast to the onedimensional perspective of Swedish curriculum.

\section{EthiCo II: From a 'what' focus to a 'how' focus on ethical competence}

In line with how education could be understood as contributing to social justice, educational research is often conducted with the ambition to contribute to improved possibilities of education, learning and, by extension, social justice. Therefore, when a broadened understanding of ethical competence is identified, the idea to try to develop knowledge about advantageous ways to learn multidimensional ethical competence is not far off.

Drawing on a pilot study financed by the Department of Pedagogical, Curricular and Professional Studies, the project 'Refining the ethical eye and ethical voice - The possibilities and challenges of a fiction-based approach to ethics education' (EthiCo II) was developed, newly funded by the Swedish Institute for Educational Research. The project team largely included the same members as comprising EthiCo: Olof Franck, Annika Lilja, Karin Sporre and the present author, including new members David Lifmark and Anna Lyngfelt.

The purpose of EthiCo II was to plan and investigate, along with schoolteachers, the extent to which and the conditions under which a fiction-based EE designed in collaboration could develop (such as multidimensional) ethical competence of 14-year-old pupils, and also to explore the difficulties that could be identified in such an EE approach. The research questions are as follows: firstly, which ethical competences do pupils at six participating schools express at the beginning and end of grade 8 ? (The project works with three schools with fiction-based teaching and three with their ordinary teaching.) Secondly, what development in ethical competence could be identified during an academic year at individual and group level of pupils, amongst those who have had fiction-based ethics teaching and those who have had their regular ethics teaching? Thirdly, which variation concerning dominant speech genres (Bakhtin 1986), as well as concerning 
the implementation of the teaching, could be identified between the three classes? Fourthly, what insights regarding the possibilities and difficulties of teaching do the teachers express during the school year? Lastly, could it be possible to identify teaching factors and classroom factors that could benefit or limit the development of ethical competence?

The theoretical underpinning of what a fiction-based approach to EE may contribute comes partly from Martha Nussbaum (2008), who stresses that through fiction we come into contact with the destinies that we would never have the chance to be part of ourselves. Through fiction we develop sympathetic imagination, and also cultivate this capacity when reading fiction so that we become skilled at using this capacity in our everyday life. Fiction and the gained ability to imagine also offer a way to develop a 'knowledge of possibilities' so that we can see and be prepared for scenarios that might happen, and have ideas about alternative actions that do not seem to be at hand but might be present. According to Nussbaum (2008), through fiction we develop new visions, hopes, possibilities and beliefs that could shape and have an impact on our ongoing recreation of reality. All these benefits could be understood as central to what we have described, primarily in relation to Rest (1986), as a multidimensional ethical competence. Perhaps fiction could be understood as being of certain value for one's moral sensitivity. To identify moral issues, to listen, to see and be empathic are a great deal of what moral sensitivity is all about. However, this in turn has direct and indirect consequences on our moral judgement, moral motivation and moral implementation.

A theoretical perspective concerning the contribution of fiction to $\mathrm{EE}$ and moral development needs to be more specific and more elaborated when it comes to why this is so and how it could be understood. Therefore, in EthiCo II, in addition to Martha Nussbaum we draw on Mark Tappan's sociocultural perspective of learning and moral development. Tappan (1998a) himself, even though in several respects he advocates the same perspectives as the character educators who plea for moral stories, has criticised this perspective for not explaining why these approaches 'are more likely to produce moral improvement than other approaches' (p. 143). Tappan (2006), in turn, drawing on Vygotsky amongst others, has stressed how higher psychological processes, such as moral functioning, are mediated through cultural tools, amongst which words, language and forms of discourse are the most central ones. Moral discourses profoundly shape our moral thinking, feeling, speaking and acting. To expand one's repertoire of moral discourses through narratives can therefore be understood as of utmost importance. Stories both read and acted socially could be understood as central. Tappan (1998a:152) quotes Volosinov, saying that "'experience exists even for the person undergoing it only in the material of signs"'.

Simultaneously, as Tappan stresses upon the importance of narratives, including those only experienced in signs, he has written more about socially represented narratives, both those we listen to and those we tell ourselves. Drawing on
Bakhtin (1986), Tappan stresses how our inner speech has the character of internalised dialogue between two or more voices. These voices gradually become our own (Tappan 1991a:248), but the words we use are still half someone else's (Tappan \& Brown 1996:103).

According to Tappan, having the opportunity to tell stories is extremely important, as telling a story inevitably means taking a moral position. Through being the author of one's story, one claims authority over, as well as responsibility for, that story and the perspectives stressed therein (Tappan 1991b; Tappan \& Brown 1989). Simultaneously, we have to be aware of how the context and practices where we tell our stories will influence what and how we tell them. The stories we tell and the stories they meet are of importance for our further moral functioning.

Consequently, for Tappan moral education is largely about creating a context where we can grow in stories told and stories heard. In accordance with Vygotsky's theory of the centrality of identifying and working with a zone of proximal development (ZPD), Tappan stresses upon the importance of children being guided by parents, teachers and more competent peers in their language-mediated moral functioning. The language used in moral practices, as Tappan (1998a:147) describes it, is a vernacular language. However, he has also stressed upon the importance of developing specific voices of both care and justice (Tappan 2006). Development in moral functioning could be understood as applying a richer repertoire of moral discourse to be able to respond to moral dilemmas in more complex and sophisticated ways (Tappan 2006). Concretely, in relation to Roland G. Tharp and Ronald Gallimore, in their book Rousing Minds to Life: Teaching, Learning, and Schooling in Social Context, Tappan (1998a) has described that children are often guided by more capable others through modelling, rewarding and punishing, feeding back, instructing, questioning and providing structures for understanding, thinking and acting. In the next stage, the learner is able to direct himself/herself in his/her inner speech. Gradually, the child's performance becomes more automatised. Tappan (1998b) has also described different educational strategies from a sociocultural perspective on learning as being in harmony with a care perspective, stressing modelling, dialogue, practice and confirmation. In relation to Nel Nodding's care perspective on ethics, Tappan (1998b) has also highlighted caring, dialogue, listening and respect as implicit value presuppositions for the sociocultural perspective of learning.

In summary, Tappan's sociocultural perspective on learning expands Nussbaum's (1990, 2008, 2011) narrative virtue ethics by offering a more elaborated theory of why narratives could be considered important to moral development and EE. In addition, this theoretical perspective directs focus towards how these narratives are used in discussions and practices.

We know very little through empirical research about the impact of fiction on EE; thus, EthiCo II could be understood 
as being of importance. The model we research comprises nine lessons, all of which have the same structure, possibly divided in four steps: Firstly, the teacher reads a story aloud; secondly, there are joint activities in relation to the story; thirdly, the pupils sit in groups and discuss the story; and lastly, the groups share their interpretations in the whole class. The stories have different focuses, but all are related to issues which, from the group interviews with pupils in EthiCo, we know pupils consider to be the situations in which ethical competence is needed. These situations concern peer relations, education and the future, climate change, migration and beggary (Osbeck 2018).

From the preliminary findings of the pilot study - recurrent audio-recorded group discussions the pupils held based on their fiction reading during one academic year - we have seen, firstly, the widening of content and moral discourses, and secondly, that the discussions develop so that the pupils become skilled in processes of importance such as critically examining, expressing alternative perspectives, raising new questions, formulating concepts and developing core formulations, and more generally motivating and arguing.

The widening of content concerns not only repertoires of stories but also repertoires of ethical perspectives, that is, what can be regarded as central to take into account when judging right/ wrong or good/bad. The pupils express rather broad repertoires. They stress upon the importance of community, principles and laws, goals and the achievement of goals, and especially focus on situations and the special conditions of a situation which could be understood as a sort of proximity ethics (Lévinas 1987; Løgstrup 1997). Together, the pupils develop insights regarding situational factors that affect people's opportunities to do right or good. Such mentioned factors include positions and thereby different dependencies, socialisation processes (e.g. influences from parents and peers), material resources (e.g. finance), knowledge and experience as well as personal qualities and feelings (e.g. thoughtfulness, spontaneity, security, courage, fear, loneliness and guilt feelings). In addition, they thematise how a seeing competence and insightfulness could affect a person's opportunities to do good.

\section{Ethical considerations}

Ethical clearance was obtained from the research ethics committee (Etikprövningsnämnden) in Gothenburg (Ethical clearance number: 06-15).

\section{Discussion}

\section{A narratively mediated multidimensional ethical competence as powerful knowledge}

Upon this background, the article discusses to what extent a multidimensional ethical competence, mediated by a multitude of narratives, of which we aim, and have reasons to believe, would develop through the EthiCo II teaching model and be understood as powerful knowledge, contributing to social mobility and social justice. One answer to this question must be that, with a strict definition of powerful knowledge such as given by Young, there is not much reason to believe that the teaching could develop powerful knowledge more than marginally. To Young (2013a:108), powerful knowledge has two key characteristics: one being that it is specialised, in 'how it is produced (in workshops, seminars and labs) and in how it is transmitted (in schools, colleges and universities)'. That it is specialised also means that in its focus it is defined by academic disciplines. Furthermore, powerful knowledge is differentiated from the experiences pupils bring to school so that the conceptual boundaries between school and everyday knowledge are clear. Although powerful knowledge is not general knowledge, it does have generalising capacities. In the area of ethics, Young stresses that Kant's principle - to treat everyone as an end in themselves and not as a means to your end - is 'powerful' because it is almost 'a generalizable (or universal) principle for how human beings should treat others' (Young 2013a:108). The teaching model in EthiCo II is not focused on ethical models or defined points of view to use in analyses. Nevertheless, the perspectives developed and identified in the pilot study could be described in such a way that the presence of different classical ethical perspectives was visible (see above).

The question must be raised as to whether Young's definition of what constitutes powerful knowledge might be seen as overly narrow. For instance, it has been regarded as important to expand the concept to also include transformations of that specialised and differentiated knowledge so that considerations concerning the selection of teaching content also take into account what could be possible for the pupils to learn (Gericke et al. 2018). The alternative is the risk of meaningless teaching. However, could a multidimensional ethical competence mediated by a multitude of narratives, which is our aim in EthiCo II, be described as powerful with a broader understanding of the concept? As shown above, there is reason to believe that you become more powerful with richer and more nuanced moral discourses mediating your moral functioning. It would affect your possibilities for moral sensitivity, moral judgement, moral motivation and moral implementation. Processes in which you gain authority and responsibility would also make you more powerful. Even if these processes are empowering and, as Young (2013b) rightly stresses, empowerment is something else than the knowledge being powerful, these processes also contribute to powerful knowledge. To better understand and explain the world, another criterion of powerful that Young uses, different kinds of discourses are of importance. Moral discourse involves not only abstract principles but, as Tappan (2006) emphasises, largely vernacular language. In addition, what becomes powerful is related to the context and the people present even if different types of moral discourses are also traditionally associated with different amounts of power.

Still, there are reasons to believe that Young's definition of powerful knowledge could fruitfully be expanded, it is important to pay attention to whether a focus on powerful knowledge in Young's interpretation could develop the teaching model of EthiCo II. Perhaps it would be useful to 
include practices in which the pupils, through interaction with more competent actors, were guided to see general patterns in the discussions they have, in a way similar to how the perspectives visible in the pilot study discussions were summarised above. In such a way, parallel to expanding their repertoire of narratives, they would also develop a metalanguage of ethics, which is in fact also a goal in the Swedish curriculum. ${ }^{2}$ With such awareness, they might perhaps also notice perspectives they have missed in their discussions of a current fiction, which could open up for further discussions of what such perspectives could mean in relation to the concrete case. Here, of importance are both the classical ethical models and the different dimensions of ethical competence developed by Rest (moral sensitivity, moral judgement, moral motivation and moral implementation).

Besides the conclusion that discourses of fiction and faction, such as in ethics textbooks, make different types of contributions that can be important in both developing powerful knowledge there are narrative discourses, as in fiction and in religious stories contributions that could only be found there. In such narratives, one finds discourses that transcend reality, discourses of the not-yet-although-then, maybe possible. Through reading and discussing stories, we develop 'knowledge of possibilities', new visions, hopes and beliefs that would shape and affect our ongoing recreation of reality. And perhaps, as stressed by Horkheimer and Adorno (2002), it could be considered extremely powerful and important to learn imagination, combined with a critically refined ethical eye through which one reveals reality and imagines alternatives and possibilities - not least in the shaping of societal justice:

Invocation of the sun is idolatry. Only the spectacle of the tree withered in its heat gives a presentiment of the majesty of the day which will not scorch the world on which it shines. (p. 202)

\section{Acknowledgements}

This study has drawn from the findings of the EthiCo research project: 'What may be learnt in ethics? Varieties of conceptions of ethical competence to be taught in compulsory school' (Dnr 2014-2030), funded by the Swedish Research Council.

\section{Competing interests}

The author declares that she has no financial or personal relationships that may have inappropriately influenced her in writing this article.

\section{Author's contributions}

C.O. is the sole author of this research article.

\section{Funding information}

Swedish National Research Council (Vetenskapsrådet) 721-2014-2030.

2.'[T] use ethical concepts and models in a basically or relatively well functioning way' (Skolverket 2011:187).

\section{Data availability statement}

Data sharing is not applicable to this study as no new data were created or analysed in this study.

\section{Disclaimer}

The views and opinions expressed in this article are those of the author and do not necessarily reflect the official policy or position of any affiliated agency of the author.

\section{References}

Afdal, G., 2005, Tolerance and curriculum: Conceptions of tolerance in the multicultura unitary Norwegian compulsory school, Det Teologiske Menighetsfakultet, Oslo.

Anker, T. \& Afdal, G., 2018, 'Relocating respect and tolerance: A practice approach in empirical philosophy', Journal of Moral Education 47(1), 48-62. https://doi.org/10. 1080/03057240.2017.1360847

Bakhtin, M., 1986, Speech genres and other late essays, University of Texas Press, Austin, TX.

Benhabib, S., 1992, Situating the self. Gender, community, and postmodernism in contemporary ethics, Routledge, New York, NY.

Benhabib, S., 2006, Another cosmopolitanism, Oxford University Press, New York, NY.

Bråten, O.M.H., 2009, A comparative study of religious education in state schools in England and Norway, University of Warwick, Warwick.

Claesson, S. \& Strandler, O., 2016, 'Sweden', in H. Döbert, W. Hörner, B. Von Kopp \& L. Reuter (eds.), Die Bildungssysteme Europas, Schneider Verlag Hohengehren, Baltmannsweiler.

Conroy, J.C., Lundie, D. \& Baumfield, V., 2012, 'Failures of meaning in religious education', Journal of Beliefs \& Values 33(3), 309-323. https://doi.org/10.1080/ 13617672.2012.732812

Frykman, J., 1998, Ljusnande framtid!: Skola, social mobilitet och kulturell identitet, Historiska Media, Lund.

Gericke, N., Hudson, B., Olin-Scheller, C. \& Stolare, M., 2018, 'Powerful knowledge, transformations and the need for empirical studies across school subjects', London Review of Education 16(3), 428-444. https://doi.org/10.18546/LRE.16.3.06

Goodlad, J. \& Su, Z., 1992, 'Organization of the curriculum', in P.W. Jackson (ed.), Handbook of research on curriculum: A project of the American Educational Research Association, pp. 327-344, Macmillan, Lund.

Horkheimer, M. \& Adorno, T.W., 2002, Dialectic of enlightenment: Philosophical fragments, Stanford University Press, Stanford, CA.

Lévinas, E., 1987, Time and the other and additional essays, Duquesne University Press, Pittsburgh, PA.

Lilja, A., Franck, O., Osbeck, C. \& Sporre, K., 2018, 'Ethical competence - A comparison between the Swedish and the Icelandic curricula and some teachers' views', Education 3-13, 46(5), 506-516. https://doi.org/10.1080/03004279.2017.1284249

Lilja, A. \& Osbeck, C., 2019, 'Understanding, acting, verbalizing and persevering Swedish teachers' perspectives on important ethical competences for students', Journal of Moral Education 1-17. https://doi.org/10.1080/03057240.2019.1678462

Lindskog, A., 2014, 'De nationella proven ireligionskunskap: Svaren på frågorna genererar nya frågor' [The national tests in religious education: The answers to the questions generate new questions], Religion \& Livsfrågor 4, 2-3.

Løgstrup, K.E., 1997, The ethical demand, University of Notre Dame Press, Notre Dame.

Mårdstedt, M. \& Wåke, C., 2014, 'Att utveckla nationella prov i religionskunskap' [To develop national tests in religious education], Religion \& Livsfrågor 4, 6-8.

Nussbaum, M.C., 1990, Love's knowledge: Essays on philosophy and literature, Oxford University Press, New York, NY.

Nussbaum, M.C., 2008, 'Democratic citizenship and the narrative imagination', Yearbook of the National Society for the Study of Education 107(1), 143-157. https://doi.org/10.1111/j.1744-7984.2008.00138.x

Nussbaum, M.C., 2011, Creating capabilities: The human development approach, Belknap Press of Harvard University Press, Cambridge, MA.

Osbeck, C., 2017, 'Ethical competences in pupils' texts - Existential understandings and ethical insights as central but tacit in the curriculum', in O. Franck (ed.) Assessment in ethics education - perspectives with special regard to national tests in religious education in Sweden, pp. 87-113, Springer, Dordrecht.

Osbeck, C., 2018, 'Values and existential understandings as parts of students' ethical competence', in J. Astley, L.J. Francis \& D.W. Lankshear (eds.), Values, human rights and religious education: Contested grounds, pp. 19-37, Peter Lang, Bern.

Osbeck, C., Franck, O., Lilja, A. \& Lindskog, A., 2015, 'Challenges of assessment in ethics - Teachers' reflections when assessing national tests', EDUCARE Vetenskapligaskrifter 2015(2), 19-47. 
Osbeck, C., Franck, O., Lilja, A. \& Sporre, K., 2018, 'Possible competences to be aimed at in ethics education - Ethical competences highlighted in educational research journals', Journal of Beliefs \& Values 39(2), 195-208. https://doi.org/10.1080/136 journals', Journal of Belie

Osbeck, C. \& Skeie, G., 2014, 'Religious education at schools in Sweden', in M. Rothgangel, G. Skeie \& M. Jäggle (eds.), Religious education at schools in Europe: Part 3: Northern Europe, pp. 237-266, V \& R Unipress, Göttingen.

Rest, J.R., 1986, Moral development: Advances in research and theory, Praeger, New York, NY.

Samuelsson, J., 2014, "̈̈mnes integrering och ämnes specialisering: SO-undervisning Sverige 1980-2014' [Subject integration and subject specialization: Social studies teaching in Sweden 1980-2014], Nordidactica: Journal of Humanities and Social Science Education 2014(1), 85-118.

Singer, P., 2011, Practical ethics, Cambridge University Press, New York, NY.

Skolverket [Swedish National Agency for Education], 2011, Curriculum for the compulsory school, preschool class and the leisure-time centre 2011, Fritzes, Stockholm.

Sporre, K., 2019, 'Assessing ethics education through nationaltests - An advantage or not?', Journal of Curriculum Studies 51(2), 262-278. https://doi.org/10.1080/002 20272.2018.1533999

Sporre, K., [in press], 'Ethics education in religious and values education frameworks Contexts, variations and suggestions for curricular development', in D. Lankshear, L. Francis \& S. Parker (eds.), Religious and values education: Contextual challenges, Peter Lang, Bern.

Tappan, M., 1991a, 'Narrative, language and moral experience', Journal of Moral Education 20(3), 243-256. https://doi.org/10.1080/0305724910200302

Tappan, M., 1991b, 'Narrative, authorship, and the development of moral authority' New Directions for Child and Adolescent Development 1991(54), 5-25. https:// doi.org/10.1002/cd.23219915403
Tappan, M., 1998a, 'Moral education in the zone of proximal development', Journal of Moral Education 27(2), 141-160. https://doi.org/10.1080/0305 724980270202

Tappan, M., 1998b, 'Sociocultural psychology and caring pedagogy: Exploring Vygotsky's “Hidden Curriculum"', Educational Psychologist 33(1), 23-33. https:// doi.org/10.1207/s15326985ep3301 2

Tappan, M.B., 2006, 'Moral functioning as mediated action', Journal of Moral Education 35(1), 1-18. https://doi.org/10.1080/03057240500495203

Tappan, M. \& Brown, L.M., 1989, 'Stories told and lessons learned: Toward a narrative approach to moral development and moral education', Harvard Educational Review 59(2), 182-206. https://doi.org/10.17763/haer.59.2. d364up55vx875411

Tappan, M. \& Brown, L.M., 1996, Envisioning a postmodern moral pedagogy, Journa of Moral Education 25(1), 101-109. https://doi.org/10.1080/0305724960250111

Tykesson, J., 2017, 'Differential item functioning in the national tests in religious education in Sweden', in O. Franck (ed.), Assessment in ethics education Perspectives with special regard to national tests in religious education in Sweden, pp. 145-162, Springer, Dordrecht.

Yang Hansen, K. \& Gustafsson, J.E., 2016, 'Causes of educational segregation in Sweden - School choice or residential segregation', Educational Research and Evaluation: An International Journal on Theory and Practice 22(1-2), 23-44. https://doi.org/10.1080/13803611.2016.1178589

Young, M., 2013a, 'Overcoming the crisis in curriculum theory: A knowledge-based approach', Journal of Curriculum Studies 45(2), 101-118. https://doi.org/10.1080/ 00220272.2013.764505

Young, M., 2013b, 'Powerful knowledge: An analytically useful concept or just a "sexy sounding term"? A response to John Beck's "Powerful knowledge, esoteri knowledge, curriculum knowledge"', Cambridge Journal of Education 43(2), 195198. https://doi.org/10.1080/0305764X.2013.776356 